

Revista de Derecho

ISSN: 2313-6944

ISSN: 2707-9651

revistaderecho@unap.edu.pe

Universidad Nacional del Altiplano

Perú

\title{
REFLEXION BOLIVIANA ENTRE EL PRESIDENCIALISMO Y LOS CABILDOS; ESTÁNDARES INTERAMERICANOS EN MATERIA DE DERECHOS HUMANOS RESPECTO A LA PROTESTA Y EL USO DE LA FUERZA
}

Arandia Arzabe, Omar

REFLEXION BOLIVIANA ENTRE EL PRESIDENCIALISMO Y LOS CABILDOS; ESTÁNDARES

INTERAMERICANOS EN MATERIA DE DERECHOS HUMANOS RESPECTO A LA PROTESTA Y EL USO DE LA FUERZA

Revista de Derecho, vol. 6, núm. 2, 2021

Universidad Nacional del Altiplano, Perú

Disponible en: https://www.redalyc. org/articulo.oa?id=671870938008

DOI: https://doi.org/10.47712/rd.2021.v6i2.152

\section{(c) (1)}

Esta obra está bajo una Licencia Creative Commons Atribución 4.0 Internacional. 


\section{REFLEXION BOLIVIANA ENTRE EL PRESIDENCIALISMO Y LOS CABILDOS; ESTÁNDARES INTERAMERICANOS EN MATERIA DE DERECHOS HUMANOS RESPECTO A LA PROTESTA Y EL USO DE LA FUERZA}

\section{BOLIVIAN REFLECTION BETWEEN THE PRESIDENTIALISM AND THE CABILDOS; INTER- AMERICAN STANDARDS ON HUMAN RIGHTS REGARDING THE PROTEST AND USE OF FORCE}

Omar Arandia Arzabe

Grupo Interamericano de Docentes Investigadores en

Derechos Humanos - GIADDHH, Estado Plurinacional de

Bolivia

oarajurista@gmail.com
DOI: https://doi.org/10.47712/rd.2021.v6i2.152 Redalyc: https://www.redalyc.org/articulo.oa? id $=671870938008$

Recepción: 04 Agosto 2021 Aprobación: 09 Septiembre 2021 Publicación: 14 Septiembre 2021

\section{Resumen:}

El texto presenta una reflexión respecto al presidencialismo y los cabildos en el caso boliviano. Asimismo, refiere los estándares aplicables en atención al uso de la fuerza y el Derecho a la protesta a fin de que la ciudadanía activa sea empoderada mediante los estándares de la Corte Interamericana de Derechos Humanos.

Palabras Clave: Bolivia, Estado Convencional de Derecho, Corte Interamericana de Derechos Humanos, Uso de la Fuerza.

\section{Abstract:}

The text presents a reflection regarding presidentialism and councils in the Bolivian case, refers to the applicable standards in attention to the use of force and protest so that active citizenship is empowered through the standards of the Inter-American Court of Human Rights.

KEYwORDs: Bolivia, Conventional State of Law, Inter-American Court of Human Rights, Use of Force.

\section{LA COMPLEJA INTERACCIÓN ENTRE EL PRESIDENCIALISMO Y LOS CABILDOS}

En Bolivia, en las últimas décadas, existe una secuencia enmarcada en la protesta, renuncia, sucesión Constitucional en atención al vacío de poder y posterior indulto respecto a delitos de sedición/terrorismo (entre otros). Ello ocurre en el marco del continuo presidencialismo (entendiéndose como la hipertrofia de poder en la figura del presidente) que, a partir de la narrativa discursiva estereotipada destruyen elementos de cohesión social, generando un desafío para la institucionalidad: un desafío que comprende superar el presidencialismo. El presidencialismo como sistema de gobierno perturbado pretende "endiosar" a la figura del presidente, en una lógica mezquina y sin permisión para que se oferten alternativas reales al tiempo en el que se vive y anclándose en tópicos antagonistas, aunado a ello, la opacidad de los programas políticos y su respectiva anhelada implementación. Los personajes que se sirven del pueblo a título de cumplir funciones públicas poseen su fuente de poder en el discurso focalizado en la insatisfacción popular, en otras palabras, un discurso antisistema. Paralelamente, existe un Parlamento sin voces propias, traducido en un parlamento

\section{NotAS DE AUTOR}


frágil desde la visión ciudadana en razón a que no cumple la lógica de representación, toda vez que el espacio que el Poder Constituyente generó, debería generar debate desde la pluralidad, aceptando la divergencia y comprendiendo las convergencias en el marco de las anheladas soluciones institucionales que aguarda la ciudadanía. Construir el proyecto país supone que se debe dialogar, no únicamente alinearse a la instructiva del partido con pensamientos sesgados y obsoletos. Es cuestión de asimilar que el legislador es digno, y la dignidad supone ser considerado como sujeto, no como objeto para la obtención de diversos fines. Resulta oportuno citar a Kant, señalaba que: “...obra de tal modo que trates a la humanidad, tanto en tu persona como en la persona de cualquier otro, siempre como un fin al mismo tiempo y nunca solamente como un medio”.[1] Kant concebía a la humanidad como un conjunto de facultades propias exclusivas de los seres humanos, facultades que son morales e intelectuales. Las facultades morales o razonables nos permiten desarrollar el sentido moral de justicia y respeto, y las intelectuales o racionales nos permiten desarrollar la cultura como cultivo o crecimiento del sujeto humano.

El maestro Rafael Aguilera Portales menciona: “... en Kant podemos observar que el valor dignidad reside en la capacidad racional que tenemos como agentes y sujetos humanos para establecer fines, es decir, por desarrollar la razón práctica, una diferencia fundamental respecto a otros seres vivos o a cualquier objeto o cosa”. [2] Es por esta razón, que la dignidad o humanidad que reside en la persona es un valor incondicional, y absoluto; los seres humanos con razón práctica que proyectan fines y objetivos sobre su vida tienen dignidad, entendiéndose como un valor en sí mismos que les otorga un estatus especial como personas.

Para construir Políticas Públicas deben existir acuerdos enmarcados en pro del bien común, en el bien de la ciudadanía como si fuere el sol de la vía láctea. Es necesario que se extiendan brazos entre ciudadanos de diferentes países para que regionalmente se puedan compartir problemas y generar soluciones de forma cotidiana, no periódica, en ese sentido, jurídicamente la Corte Interamericana de Derechos Humanos mediante sus estándares jurisprudenciales permite generar lazos jurídicos en la región en aras de la construcción de Estados Convencionales de Derecho. El presidencialismo aunado a la política de los extremos mediante una diégesis procura instaurar un modelo pretendiendo olvidar que en el pasado se ofrecieron modelos que no funcionaron. Casualmente entre muchas razones porque no existen fórmulas para el idilio. En la actualidad en la región es posible percibir fraccionamiento, contraposición y no oposición. El proyecto debe generar un discurso de impacto viral que denote la forma de construcción política, no la supuesta solución. El ímpetu del ciudadano frustrado con el sistema es aprovechado por la narrativa extremista. El hastiado ciudadano es víctima y prisionero del Gobierno. En ese marco, surgen las protestas y la labor del Tribunal Constitucional va a suponer una labor trascendental para generar un sostén institucional del Estado, en el entendido que las peticiones sean canalizadas. La vorágine de bloqueos y caos no es generada por un hecho aislado, sino que en Bolivia existe un termómetro social que cuando llega un punto de falta de respuesta institucional en razón a las peticiones no correspondidas, tiende a explotar.

El Estado debe ser capaz de vislumbrar la legitimidad de las peticiones y apartarse del formalismo y la improvisación. La ciudadanía se expresa día a día en las calles. ejerciendo su Derecho a la protesta, pretender desconocer ello mediante mecanismos de carácter jurídico o político genera una sensación de insatisfacción ciudadana. Un claro ejemplo supone el tópico del cabildo: cuando existe un cabildo en Bolivia, el Órgano Electoral debería elaborar el informe (posterior a la observación y el acompañamiento al cabildo) y publicarlo en su página web (Arts. 37 y 38 de la Ley del Régimen Electoral Boliviano). [3] Sin embargo, es necesario preguntarse si la ciudadanía en general cuestiona al mismo Estado en su institucionalidad ¿será congruente que las instituciones del Estado tengan que observar e informar respecto al cabildo cuando su legitimidad es la cuestionada? Considero necesario recordar un concepto clave: autoridad. La autoridad supone básicamente la composición de dos elementos centrales: aquella normativa que faculta a instituir el cargo y la moralidad para ejercer el cargo ¿será lógico que el ciudadano que no obtuvo una respuesta institucional para un asunto pueda esperar una respuesta del mismo Estado? Para que ello ocurra el Estado requiere de credibilidad y cuando la confianza se quiebra, el Estado para el ciudadano no es merecedor de que exista relación entre 
la sociedad-gobierno, entonces ello conduce a que exijan reformas serias y en caso de no existirlas se sigue en el mismo bucle; un círculo que generaciones vislumbran, hasta que llegue la generación del "yo no me dejo" y para ese momento la ciudadanía debe hallarse a sí misma empoderada de estándares regionales de la Corte Interamericana de Derechos Humanos y debe poder activar las garantías de no repetición respecto a la Supervisión de Cumplimiento de Sentencias de la Corte. Entonces, en el camino, surgen luces. En la actualidad, la ciudadanía boliviana en general asume un rol activo en los asuntos públicos. El activismo cibernético posibilita que se generen cadenas virales de peticiones y protestas en las redes sociales a partir de movimientos en los cuales la ciudadanía planta algunas banderas de lucha, por ejemplo, en tópicos de género, medio ambiente y convivencia plural. Sin embargo, no existe admisión en espacios de toma de decisión, toda vez que el poder político posterior a las elecciones no efectúa una sinergia con el propio votante en el quehacer diario de la gestión gubernamental, aunado a ello, el poder político osa despilfarrar recursos públicos en constante campaña política. La ciudadanía exige que la participación revista de características vinculantes de forma constante. Ante tal escenario, los cabildos pueden ser un mecanismo transformador de paradigma en el cual, el sistema político canalice la sinergia. La ciudadanía requiere que la participación sea institucionalizada y un medio por el cual se puede participar es la tecnología, en ese marco sería interesante generar cabildos digitales porque las peticiones sociales en pleno siglo XXI no son canalizadas institucionalmente -en generaldenotando una sensación de lejanía de la ciudadanía frente al Estado. Sin embargo, la ciudadanía a partir de la tecnología, el activismo en redes sociales, genera viralización de causas de bien común y de control social frente a varios hechos que socavan el bien común, como hechos de corrupción, promesas que no se cumplen, clientelismo, entre otros.

En ese marco, la tecnología es una herramienta de construcción mediante el activismo, sin embargo, reiteramos que debe ser visibilizada a partir de estándares establecidos por la Corte Interamericana de Derechos Humanos. En Bolivia, la aplicación de la jurisprudencia interamericana es de carácter preferente de aplicación en atención al Art. 256 de la Constitución Política del Estado boliviano,[4] y forma parte del Bloque de Constitucionalidad (Art. 410 de la Constitución boliviana) que incorpora a partir del año 2009 un denso contenido sustantivo formado por principios, valores, derechos fundamentales o como como señala el profesor Prieto Sanchis: “... la Constitución no sólo establece quién manda y cómo se manda, sino que pretende condicionar también en una amplia medida qué puede o debe mandarse..”.[5] Es necesario que se promocione la Convencionalidad, para que la ciudadanía impulse la construcción del Estado Convencional de Derecho, los estándares son claros. Sin dudas, empoderar a la ciudadanía en materia de Derechos Humanos contribuirá al sostén de la Democracia en la región.

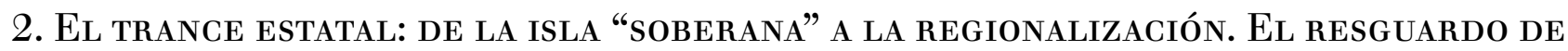 LA ConvencionalidAD RESPECTO AL USO DE LA FUERZA Y EL DERECHO A LA PROTESTA A la luz de la Corte Interamericana de Derechos Humanos}

Cuando la protesta de las redes sociales se traslada del Órgano Legislativo al Tribunal Constitucional es posible percibir que la ciudadanía reclama y al mismo tiempo tiene la esperanza que el Tribunal Constitucional resguarde el sistema de pesos y contrapesos. En ese marco, por los compromisos estatales en materia de Derechos Humanos, es posible expresar que se brinda un espacio de transición del Estado concebido como una isla soberana, hacia la regionalización mediante el fortalecimiento de los Derechos Humanos y la construcción del Estado Convencional de Derecho. En ese orden de ideas, surge un proceso de autopoiesis jurídica en relación al diálogo entre el Estado y los estándares interamericanos.

Lo anterior lleva a reflexionar sobre la Historia que una y otra vez ha demostrado fehacientemente que los Derechos son una construcción de consecuentes conquistas por parte de la ciudadanía. En el presente, la Corte Interamericana Derechos Humanos contribuye con sus estándares a construir las herramientas 
para robustecer la ciudadanía activa. Por ello, es importante entender y asumir el rol que corresponde en el entendido que ya se conoce la dirección; la meta a la cual se desea arribar.

Tomemos como ejemplo el caso Mujeres Víctimas de Tortura Sexual en Atenco vs. México.[6] Aquí, la Corte Interamericana refirió que la Policía, mediante sus agentes, generaron una instrumentalización de las mujeres detenidas a partir de sus cuerpos; con la finalidad -entre otras- de enviar un mensaje de represión y desaprobación la protesta de las personas que se manifestaron. Entonces, procedieron a cosificar a las mujeres para que estos hechos una vez conocidos por la sociedad, tuvieran el efecto de humillar, atemorizar e intimidar a quienes se manifiesten en contra de la potestad de mando. En ese marco, la Corte considero que el mensaje contenido en la represión fue utilizado como una táctica a fin de que la protesta sea dispersada y no se cuestione al Estado. La Corte concluyó además que la violencia sexual no puede ser un mecanismo de control del orden público. En el mismo caso,[7] la Corte refirió que frente al ejercicio del Derecho a la protesta, los Estados a tiempo de efectuar la evaluación del riesgo respecto al orden público y la discrecionalidad, que, la discreción no es de carácter ilimitado. Por consiguiente, el Estado debe demostrar la adopción de medidas con criterio de necesidad y proporcionalidad en atención al riesgo percibido al orden público o a los Derechos de las personas, no violentando arbitrariamente el Derecho a la reunión pacífica. El paradigma no debe comprender el trato de enemigo a la población civil, sino por el contrario: su protección. La Corte[8] refirió en aquella oportunidad, que usar la fuerza supone una medida de carácter excepcional: extrema, y su aplicación supone que no se la emplee a menos que sea inevitable.

Asimismo, la Corte, resaltó en el caso Cabrera García y Montiel Flores vs. México[9], que, los Estados deben ser cuidadosos respecto al uso de las Fuerzas Armadas respecto a la protesta, disturbios, violencia interna, criminalidad común y situaciones excepcionales. Por otro lado, en el caso Perozo y otros vs. Venezuela,[10] refirió que el uso de la fuerza y de instrumentos de coerción debe ser de forma excepcional y los demás medios existentes debieron agotarse o fracasar. Por ende, se debe distinguir quienes constituyen una amenaza inminente de muerte o lesión grave para sí mismos o para terceros, y las personas que se manifiestan y no presentan esta amenaza. Los Estados tienen que adoptar medidas de carácter razonable y adecuado para que las manifestaciones se efectúen de forma pacífica. De igual manera, en el caso Zambrano Vélez y otros vs. Ecuador,[11] la Corte refiere que las funciones policiales y militares deben circunscribirse en prevenir y proteger Derechos. Por consiguiente, en el caso Ríos y otros vs. Venezuela,[12] la Corte refirió que la difusión de información o ideas también comprenden aquellas expresiones cuyo contenido desagradable para el Estado o cualquier sector de la población. La Corte destacó que el pluralismo implica tolerancia y espíritu de apertura, aspectos sin los cuales no existiría una sociedad democrática. Cabe destacar que más recientemente, en el caso Álvarez Ramos vs. Venezuela,[13] la Corte refirió que si no existe una libertad de expresión efectiva y que se materialice se desvanece entonces la Democracia, se quebranta el pluralismo y la tolerancia se tornan inoperantes los mecanismos de control, de denuncia ciudadana y se crea un campo para que sistemas autoritarios se generen en la sociedad.

\section{Límites AL PODER ESTATAL EN EL CONTEXTO DEL USO DE LA FUERZA DURANTe LA PROTESTA}

En primera instancia, cabe manifestar que, la Corte Interamericana de Derechos Humanos, en el Caso Perozo y otros vs. Venezuela, [14] refirió que las medidas que deben adoptar los Estados en circunstancias de protesta social y manifestaciones públicas deben ser razonables y adecuadas a fin de que estas se desarrollen pacíficamente. El uso de la fuerza en contextos de protesta, también fue abordado, en el Caso Mujeres Víctimas de Tortura Sexual en Atenco vs. México.[15] Allí, la Corte sostuvo que los Estados están obligados a brindar garantías respecto a la seguridad y el orden público en su territorio. Para tal cometido, el Estado tiene la facultad para emplear de forma legítima el uso de la fuerza y para restablecer el orden si fuere necesario. Así refiere que, el uso de la fuerza letal es recurrible en algunas circunstancias, sin embargo, el Estado no posee 
facultades ilimitadas para alcanzar los fines de forma independiente a las acciones y a la culpabilidad de los autores. Asimismo, subraya que el Estado debe regular el uso de la fuerza mediante su sistema jurídico (debe existir claridad y efectividad). De igual manera, el Estado debe efectuar además la respectiva capacitación y entrenamiento a la fuerza pública respecto al sistema jurídico en materia de Derechos Humanos, en el marco de las limitaciones y condiciones respecto a las circunstancias y el uso de la fuerza. Además, el Estado debe instituir mecanismos para controlar y verificar la legitimidad del uso de la fuerza. Por otro lado, la Corte señala que los principios de legalidad, absoluta necesidad y proporcionalidad deben ser satisfechos en atención al uso de la fuerza. En primer lugar, la legalidad respecto al uso de la fuerza supone que debe existir regulación jurídica basada en una ley que prevea la actuación en ese tipo de situaciones y además exista un objeto legítimo. Por otro lado, la absoluta necesidad respecto al uso de la fuerza, supone que el uso debe ser limitado a la disponibilidad de otros medios que protejan la persona o situación, o que no existan otros medios disponibles en atención a las circunstancias. Finalmente, la proporcionalidad respecto al uso de la fuerza supone que los medios y métodos empleados deben ser correlacionales a la resistencia y al peligro existente. Habiendo hecho estas consideraciones, la fuerza pública debe efectuar un uso progresivo y diferenciado de la fuerza. Se debe determinar el grado de cooperación, resistencia o agresión respecto al sujeto que se intervendría, se deben efectuar tácticas de negociación, control o uso de la fuerza, la Corte subraya que para efectuar el examen de proporcionalidad deben analizarse las circunstancias y el contexto.

Por otro lado, la Corte Interamericana de Derechos Humanos, en el caso Díaz Loreto y otros vs. Venezuela,[16] aludió la postura de las Naciones Unidas respecto al uso de armas de fuego en atención a tres criterios: en defensa propia o de otras personas, en peligro inminente de muerte o lesiones graves; evitar la comisión de delitos que se constituyan en amenazas para la vida; a objeto de detener a la persona que represente ese peligro y oponga resistencia a su autoridad, o para impedir la fuga cuando otras medidas sean insuficientes. En ese sentido, la Corte, en el caso García Ibarra y otros vs. Ecuador[17], refirió que el uso de fuerza tiene su base en la legalidad. Si el uso de la fuerza no tuviese esa base, no se aplican los estándares de análisis de acción u omisión estatal. En suma, la Corte considera las acciones preventivas, acciones concomitantes a los hechos y acciones posteriores a los hechos. Adicionalmente, en el caso García Ibarra y otros vs. Ecuador,[18] se reafirmó que el uso de armas de fuego se encuentra previsto como medida de último recurso desde la óptica del Derecho interno e internacional.

Por otro lado, la Corte Interamericana de Derechos Humanos en el caso Álvarez Ramos vs. Venezuela,[19] reiteró que la actividad periodística es indispensable para la preservación de la democracia, y, el ejercicio libre de la actividad periodística está protegido por la Convención Americana de Derechos Humanos: ello supone que se excluye la tipicidad penal o que la actividad periodística sea considerada como delito y objeto de penas. Asimismo, la Corte, refirió que la utilización de la Ley Penal en perjuicio a la difusión de noticias produce directa o indirectamente amedrentamiento que limita la libertad de expresión, en razón a que se impediría someter al escrutinio público las conductas que vulneran el sistema jurídico, por ejemplo, en temas de corrupción. La Corte, resaltó que el Derecho Penal como respuesta punitiva por parte del Estado no procede convencionalmente a fin de proteger el honor del funcionario público. Asimismo, la Corte en el caso Usón Ramírez vs. Venezuela,[20] expresó que las opiniones no son objeto de sanción, ellas ni tampoco deben considerarse como verdaderas o falsas. Rememorando, la Corte en el caso Myrna Mack Chang vs. Guatemala,[21] afirmó que los poderes públicos no pueden utilizar como escudo el secreto de Estado para generar dificultades o evitar que se investiguen los ilícitos y la clasificación en calidad de secreta la información y su consecuente denegación no puede ser de dependencia exclusiva de un órgano estatal. La Corte, en el caso Vélez Restrepo y Familiares vs. Colombia,[22] infirió que es posible identificar a personal de la prensa en razón a portar una cámara de vídeo. En ese marco, la Corte sostuvo que las agresiones se efectuaron contra el señor Vélez a fin de impedir que proceda con la grabación de los sucesos en el entendido de que la fuerza pública pretendía impedir que difunda lo que había grabado. Entonces, la Corte determino que difundir la información permite que se constate y se controle la utilización adecuada de la fuerza pública en el marco de 
sus funciones. Por otro lado, la Corte en el caso Tristán Donoso vs. Panamá,[23] reafirmó la protección de la libertad de expresión, de la opinión o afirmación respecto a asuntos de legítimo interés de información de la sociedad, asimismo de conocimiento sobre el funcionamiento del Estado, afectación de intereses o derechos generales o consecuencias importantes para la población.

\section{A MANERA DE CONCLUSIÓN}

La aplicación de estándares interamericanos es un canal válido para que los Estados generen el proceso de autopoiesis de Convencionalidad y se genere la transición hacia el Estado Convencional de Derecho, constituyendo en el Estado boliviano y la región americana un inmejorable instrumento de legitimidad para la vida política, social y jurídica de los ciudadanos. Ello va a requerir la noble y ardua labor en la supervisión de ejecución de las sentencias de la Corte Interamericana de Derechos Humanos, toda vez que, a partir fundamentalmente de las garantías de no repetición, los ciudadanos pueden activar las vías que correspondan en atención a los casos sentenciados contra el Estado. Sin lugar a dudas, ello supone el fortalecimiento de la Corte respecto al número de funcionarios y por otro lado, respecto a ciudadanos activos empoderados de la región americana. El presidencialismo será superado con la construcción de la institucionalidad. Los estándares de la Corte, se presentan como herramientas para el resguardo de la protesta de la ciudadanía activa en diferentes espacios y el uso de la fuerza debe obedecer a los criterios de legalidad, necesidad y proporcionalidad, entendiéndose que la protesta pacífica ejercida por la ciudadanía es protegida jurídicamente por la jurisprudencia vinculante de la Corte Interamericana de Derechos Humanos.

\section{REFERENCIAS}

AGUILERA, Rafael Constitución y Democracia: Fundamentos Políticos del Estado de Derecho Ed. Grijley, Lima Perú, 2011.

ARANDIA GUZMÁN, Omar; ARANDIA ARZABE Omar. El Control de Convencionalidad y la juridicidad de los Derechos Humanos en la aplicación de Medidas Cautelares. Ed. Kipus, Cochabamba, 2016

BOLIVIA, Constitución Política del Estado Plurinacional, Ed. El Original, 2009.

Ferrer Mac Gregor, Eduardo-ZALDIVAR, Arturo La Ciencia del Derecho Procesal Constitucional, Estudios en homenaje a Hector Fix Zamudio, Ed. Marcial Pons México, 2013.

KANT, Immanuel Metafísica de las costumbres, 2da. Ed. Trd. Cortina y J. Conill Tecnos, Madrid, 1996.

Corte IDH, Caso Álvarez Ramos vs. Venezuela, Sentencia de 30 de agosto de 2019, Excepciones Preliminares, Fondo, Reparaciones y Costas.

Corte IDH, Cabrera García y Montiel Flores vs. México, Sentencia de 26 de noviembre de 2010, Excepciones Preliminares, Fondo, Reparaciones y Costas.

Corte IDH, Caso Mujeres Víctimas de Tortura Sexual en Atenco vs. México de Sentencia 28 de noviembre de 2018, Excepciones Preliminares, Fondo, Reparaciones y Costas.

Corte IDH, Caso Díaz Loreto y otros vs. Venezuela, Sentencia de 19 de noviembre de 2019, Excepciones Preliminares, Fondo, Reparaciones y Costas.

Corte IDH, Caso García Ibarra y otros vs. Ecuador, Sentencia de 17 de noviembre de 2015, Excepciones Preliminares, Fondo, Reparaciones y Costas.

Corte IDH, Caso Myrna Mack Chang vs. Guatemala, Sentencia de 25 de noviembre de 2003, Excepciones Preliminares, Fondo, Reparaciones y Costas.

Corte IDH, Caso Perozo y otros vs. Venezuela, Sentencia de 28 de enero de 2009, Excepciones Preliminares, Fondo, Reparaciones y Costas. 
Corte IDH, Caso Ríos y otros vs. Venezuela, Sentencia de 28 de enero de 2009, Excepciones Preliminares, Fondo, Reparaciones y Costas.

Corte IDH, Caso Tristán Donoso vs. Panamá, Sentencia de 27 de enero de 2009, Excepciones Preliminares, Fondo, Reparaciones y Costas.

Corte IDH, Caso Usón Ramírez vs. Venezuela, Sentencia de 20 de noviembre de 2009, Excepciones Preliminares, Fondo, Reparaciones y Costas.

Corte IDH, Caso Vélez Restrepo y Familiares vs. Colombia, Sentencia de 3 de septiembre de 2012, Excepciones Preliminares, Fondo, Reparaciones y Costas.

Corte IDH, Caso Zambrano Vélez y otros vs. Ecuador Sentencia de 4 de julio de 2007, Excepciones Preliminares, Fondo, Reparaciones y Costas.

\section{Notas}

[1]Immanuel Kant: Metafísica de las costumbres, Tecnos, Madrid, 1996, p. 96.

[2]Rafael Aguilera: Constitución y Democracia: Fundamentos Políticos del Estado de Derecho, Grijley, Lima, 2011, p. 75.

[3]Ley 026, Ley del Régimen Electoral Boliviano, de 30 de junio de 2010

[4]Constitución Política del Estado de Bolivia, de 07 de febrero de 2009

[5]Eduardo Ferrer Mac Gregor-Arturo Zaldivar: La Ciencia del Derecho Procesal Constitucional, Estudios en homenaje a Héctor Fix Zamudio, Marcial Pons México, 2013, p. 807.

[6]Corte IDH, Caso Mujeres Víctimas de Tortura Sexual en Atenco vs. México de Sentencia 28 de noviembre de 2018, Excepciones Preliminares, Fondo, Reparaciones y Costas, párrafo 167.

[8]Corte IDH, Caso Mujeres Víctimas de Tortura Sexual en Atenco vs. México de Sentencia 28 de noviembre de 2018, Excepciones Preliminares, Fondo, Reparaciones y Costas, párrafo 249.

[9]Corte IDH, Cabrera García y Montiel Flores vs. México, Sentencia de 26 de noviembre de 2010, Excepciones Preliminares, Fondo, Reparaciones y Costas, párrafo 87.

[10]Corte IDH, Caso Perozo y otros vs. Venezuela, Sentencia de 28 de enero de 2009, Excepciones Preliminares, Fondo, Reparaciones y Costas, párrafo 166.

[10]Corte IDH, Caso Perozo y otros vs. Venezuela, Sentencia de 28 de enero de 2009, Excepciones Preliminares, Fondo, Reparaciones y Costas, párrafo 166.

[11]Corte IDH, Caso Zambrano Vélez y otros vs. Ecuador Sentencia de 4 de julio de 2007, Excepciones Preliminares, Fondo, Reparaciones y Costas, párrafo 51.

[12]Corte IDH, Caso Ríos y otros vs. Venezuela, Sentencia de 28 de enero de 2009, Excepciones Preliminares, Fondo, Reparaciones y Costas, párrafo 105.

[13]Corte IDH, Caso Álvarez Ramos vs. Venezuela, Sentencia de 30 de agosto de 2019, Excepciones Preliminares, Fondo, Reparaciones y Costas, párrafo 95.

[14]Corte IDH, Caso Perozo y otros vs. Venezuela, Sentencia de 28 de enero de 2009, Excepciones Preliminares, Fondo, Reparaciones y Costas, párrafo 166.

[15]Corte IDH, Caso Mujeres Víctimas de Tortura Sexual en Atenco vs. México, Sentencia de 28 de noviembre de 2018, Excepciones Preliminares, Fondo, Reparaciones y Costas, párrafos 159-163.

[16]Corte IDH, Caso Díaz Loreto y otros vs. Venezuela, Sentencia de 19 de noviembre de 2019, Excepciones Preliminares, Fondo, Reparaciones y Costas, párrafo 73. 
Omar Arandia Arzabe. REFLEXION bOLIVIANA ENTRE EL PRESIDENCIALISMO Y LOS CABILDOS; ESTÁNDARES INTE...

[17]Corte IDH, Caso García Ibarra y otros vs. Ecuador, Sentencia de 17 de noviembre de 2015, Excepciones Preliminares, Fondo, Reparaciones y Costas, párrafo 109.

[18]Corte IDH, Caso García Ibarra y otros vs. Ecuador, Sentencia de 17 de noviembre de 2015, Excepciones Preliminares, Fondo, Reparaciones y Costas, párrafo 112.

[19]Corte IDH, Caso Álvarez Ramos vs. Venezuela, Sentencia de 30 de agosto de 2019, Excepciones Preliminares, Fondo, Reparaciones y Costas, párrafos 121-124.

[20]Corte IDH, Caso Usón Ramírez vs. Venezuela, Sentencia de 20 de noviembre de 2009, Excepciones Preliminares, Fondo, Reparaciones y Costas, párrafo 86.

[21]Corte IDH, Caso Myrna Mack Chang vs. Guatemala, Sentencia de 25 de noviembre de 2003, Excepciones Preliminares, Fondo, Reparaciones y Costas, párrafo 181.

[22]Corte IDH, Caso Vélez Restrepo y Familiares vs. Colombia, Sentencia de 3 de septiembre de 2012, Excepciones Preliminares, Fondo, Reparaciones y Costas, párrafos 144-145.

[23]Corte IDH, Caso Tristán Donoso vs. Panamá, Sentencia de 27 de enero de 2009, Excepciones Preliminares, Fondo, Reparaciones y Costas, párrafo 121. 